\title{
INEFICACIA DE LA CRIMINALIZACIÓN DE AGRESIONES FÍSICAS CONTRA MUJERES O INTEGRANTES DEL GRUPO FAMILIAR EN DISTRITO JUDICIAL TACNA - 2017.
}

\author{
INEFFICIENCY OF THE CRIMINALIZATION OF PHYSICAL AGGRESSIONS AGAINST WOMEN OR \\ MEMBERS OF THE FAMILY GROUP IN TACNA JUDICIAL DISTRICT - 2017.
}

\author{
Ivette Aracelli Muguerza Casas ${ }^{1}$ \\ Hugo Heriberto Soza Mesta²
}

Aceptado: $17 / 09 / 2019$

Publicado online:15/01/2020

\section{RESUMEN}

El presente trabajo de investigación se llevó a cabo con el propósito de determinar en qué medida la criminalización de las agresiones físicas contra las mujeres o integrantes del grupo familiar, en el artículo 122-B del Código Penal, resultaría ineficaz, en el distrito judicial de Tacna, Año 2017. La criminalización de las agresiones físicas contra mujeres o integrantes del grupo familiar, en el artículo 122-B del Código Penal, resulta ineficaz en alta medida, porque contrastado con la realidad, en lugar de evitar su comisión y afianzar el principio de unidad familiar, genera desintegración de la familia y desprotección de la víctima, en el distrito judicial de Tacna, año 2017. El trabajo corresponde a una investigación, socio jurídico, no experimental de corte transversal. Para tal propósito se consideró la información obtenida a través de la aplicación del Cuestionarios dirigidos a magistrados y abogados, así como la obtenida a través de la Guía de revisión documental aplicada a los procesos judiciales concluidos por el delito de agresiones contra mujeres o integrantes del grupo familiar, del año 2017. El efecto intimidatorio de la criminalización de las agresiones físicas contra mujeres o integrantes del grupo familiar, previsto en el artículo 122-B del Código Penal, resulta ineficaz en alta medida, para disuadir su

\footnotetext{
${ }^{1}$ Maestro en Derecho con mención en ciencias penales. Ministerio público de Tacna-Fiscalía Provincial Penal Corporativa de Tacna. Asistente en función fiscal, Tacna, Perú

2 Doctor en Derecho, Gerente General del Estudio Soza y Asociación SAC., Académico de la Escuela de Postgrado de la Universidad Privada de Tacna, Tacna, Perú
} 
comisión y afianzar el mantenimiento del orden familiar y social, generando así desintegración de la familia y desprotección de la víctima; y la condena a pena privativa de libertad, por el delito de agresiones físicas contra mujeres o integrantes del grupo familiar, previsto en el artículo 122-B del Código Penal, resulta ineficaz en alta medida, para cumplir con el efecto resocializador de la pena.

Palabras clave: Criminalización de agresiones físicas, mujer, integrantes del grupo familiar.

\begin{abstract}
The present investigation work was carried out with the purpose of determining to what extent the criminalization of physical aggressions against women or members of the family group, in article 122-B of the Criminal Code, would be ineffective, in the judicial district of Tacna, Year 2017. The criminalization of physical aggressions against women or members of the family group, in article 122-B of the Criminal Code, is ineffective to a large extent, because contrasted with reality, instead of avoiding their commission and strengthening the principle of family unity, generates family disintegration and unprotection of the victim, in the judicial district of Tacna, 2017. The work corresponds to an investigation, legal, non-experimental cross-sectional partner. For this purpose, the information obtained through the application of the Questionnaires addressed to magistrates and lawyers was considered, as well as that obtained through the Document Review Guide applied to the judicial proceedings concluded for the crime of aggressions against women or group members. family, of the year 2017. The intimidating effect of the criminalization of physical aggressions against women or members of the family group, provided for in article 122-B of the Criminal Code, is ineffective to a great extent, to deter their commission and strengthen the maintenance of family and social order, thus generating disintegration of the family and unprotection of the victim; and the sentence of imprisonment for the crime of physical aggressions against women or members of the family group, provided for in article 122-B of the Criminal Code, is ineffective to a great extent, to comply with the resocializing effect of the penalty.
\end{abstract}

Keywords: Criminalization of physical aggressions, women, family group members..

\title{
INTRODUCCIÓN
}

El Estado peruano, ante el crecimiento alarmante de la tasa de violencia familiar, lejos de combatirlo extrapenalmente, en lugar de rediseñar y fortalecer su política social, económica y criminal, tendiente a neutralizar sus causas, para prevenir y combatir ésta criminalidad doméstica, recurrió de manera facilista al derecho penal que debe ser el 
último recurso de Estado, conforme a los Principios de Subsidiariedad y Fragmentariedad, ha respondido, apelando a una política criminal de criminalización, criminalizando conductas que de cualquier modo cause lesiones a una mujer por su condición de tal o a integrantes del grupo familiar que requieran menos de diez días de asistencia o descanso, en cualquiera de los contextos previstos en el primer párrafo del artículo 108-B del Código Penal, sancionando su comisión con pena privativa de libertad de uno a tres años, el 05 de enero de 2017, mediante la promulgación del Decreto Legislativo $\mathrm{N}^{\circ} 1323$, posteriormente, se neocriminalizó, promulgando la Ley $\mathrm{N}^{\circ} 30710$, publicado el 29 de diciembre del 2017 que, modificó el artículo 57 del Código Penal, prescribiendo que la suspensión de la ejecución de la pena, es inaplicable para las personas condenadas por el delito previsto en el artículo 122-B del Código Penal (es decir, el agresor, hermano, padre, etc., ingresará inevitablemente al establecimiento penitenciario.

El Estado Peruano, para afrontar toda forma de violencia familiar, el 25 de junio de 1997, dictó el Decreto Supremo 006-97-JUS que, aprobó el Texto Único Ordenado de la Ley Nº 26260, "Ley de Protección frente a la Violencia Familiar" y su modificatoria Ley N²6763. Sin embargo, ésta Ley de protección frente a la violencia familiar, fue tornando a las sentencias, dictadas en el marco de ésta Ley, por el Poder Judicial (Juzgado Especializado de Familia o Mixto), en simbólicas. En efecto, ésta Ley, confirió competencia a la Policía Nacional y al Fiscal de Familia o Mixto, para conocer denuncia por violencia familiar y realizar las investigaciones correspondientes y a solicitud de la víctima, se podía brindar las garantías necesarias, en resguardo de su integridad (retiro del agresor del domicilio, impedimento de acoso a la víctima, entre otros, que garanticen su integridad física, psíquica y moral).

Ante el incremento de la tasa de violencia familiar, pues, según la Encuesta Nacional Demográfica y de Salud Familiar - ENDES 2017 (INEI, 2018), el 65,4 \% de las mujeres alguna vez unidas sufrieron algún tipo de violencia por parte del esposo o compañero; el $81.3 \%$ de adolescentes de 12 a 17 años alguna vez fueron víctimas de violencia psicológica o física por parte de las personas con las que vive; el $73,8 \%$ de niñas y niños de 9 a 11 años alguna vez fueron víctimas de violencia psicológica o física por parte de las personas con las que vive. Para disminuir y prevenir ésta criminalidad doméstica, decidió recurrir al derecho penal que debe ser el último recurso de Estado, conforme a los Principios de Subsidiariedad y Fragmentariedad, para penalizar la violencia familiar, mediante la promulgación del Decreto Legislativo N¹323 (2017), criminalizando "la conducta que de cualquier modo cause lesiones a una mujer por su condición de tal o a integrantes del grupo familiar que requieran menos de diez días de asistencia o descanso o algún tipo de afectación psicológica, cognitiva o conductual en cualquiera de los contextos previstos en el primer párrafo del artículo 108-B del Código Penal" En la realidad, la tasa de violencia doméstica, ha seguido incrementando, agudizando, el problema socio familiar. Cabrera, refiere que se está exacerbando la pena cuando la lesión se produce en contra de la mujer por su condición de tal, pues ello debe ser sancionado por igual si es que el hecho es en contra de un hombre o de una mujer, evidenciándose una situación de desigualdad (Cabrera, 2018). Álvarez, publica que: "El código penal, deben ser materia de modificatoria, incorporación y derogatoria 
legislativa, debiendo incidir sobre: principios que declaren a los derechos subjetivos del conflicto de violencia familiar" (Alvarez, 2017). Rafael Bautista, concluye que "En nuestro país las leyes que versan sobre violencia familiar han ido cambiando hasta implementar un nuevo procedimiento regulado en la Ley $N^{\circ} 30364$, la misma que no es suficiente (Rafael Bautista, 2017). Rivas La Madrid, a modo de conclusión refiere que: "Las lesiones levísimas no debería ser criminalizadas, resultando innecesario, debiendo discriminarse cuándo nos encontramos ante la presencia de un evento con características de conflicto familiar (Rivas La Madrid, 2018). González Ramírez, concluye: "El campo de acción de los mecanismos colaborativos como el de la mediación en violencia debiera definirse no a partir del delito, sino a partir de la vulnerabilidad de la víctima y del reconocimiento e intención de reparar del infractor (González Ramírez, 2013). Zaffaroni et al. sostiene que "El sistema penal opera ejerciendo un poder punitivo represivo en forma de criminalización primaria y secundaria" y que "El poder punitivo se reparte en la sociedad como una enfermedad infecciosa que alcanza a los que son vulnerables" (Zaffaroni \& Alagia, \& Slokar, 2005, pp. 9-10). Villavicencio opina que "La criminalización primaria se trata de un acto formal, fundamentalmente programático" (Villavicencio, 2017, p. 11). Castillo Aparicio señala que "A diferencia de otros países, en el Perú tradicionalmente no se ha creado un tipo penal específico que sancione la violencia familiar, sino que dentro de los tipos penales ya existentes se ha agregado agravantes por razón de violencia familiar". Reátegui sostiene que "La finalidad de la regulación legal es erradicar los altos índices de maltrato hacia las mujeres por cuestiones de género, requiere un cambio necesario y que en un estado constitucional de derecho no pueden admitirse tales prácticas" (Reátegui, 2017, pp.51-52).

\section{OBJETIVOS Error! Bookmark not defined.}

a) Identificar en qué medida el efecto intimidatorio de la criminalización de las agresiones físicas contra mujeres o integrantes del grupo familiar, previsto en el artículo 122-B del Código Penal, resultaría ineficaz para evitar su comisión.

b) Medir en qué medida la condena a pena privativa de libertad, por el delito de agresiones físicas contra mujeres o integrantes del grupo familiar, previsto en el artículo 122-B del Código Penal, en los expedientes judiciales concluidos, resultaría ineficaz para cumplir con el efecto resocializador de la pena.

\section{METODOLOGÍA}

El Diseño de Investigación es no experimental descriptiva de corte transversal, enfoque mixto (cuantitativo - cualitativo). Comprende desde la entrada en vigencia de artículo 122-B del Código Penal, incorporada por el Artículo 2 del Decreto Legislativo $\mathrm{N}^{\circ} 1323$, publicado el 06 enero 2017, comprendiendo el año 2017. La muestra de trabajo estuvo constituida por 14 magistrados, 73 abogados colegiados de Tacna, y 20 expedientes judiciales concluidos. Se utilizó la técnica de la encuesta, análisis documental y observación, mediante un Cuestionario, ficha de guía de revisión documental y ficha de observación documental. 


\section{RESULTADOS}

El 100\% de los magistrados manifiestan en el artículo 122-B del Código Penal, se vulnera el Principio de Mínima Intervención del Derecho Penal (Subsidiariedad y Fragmentariedad). El 86\% afirma que vulnera el Principio de Proporcionalidad, el Principio de lesividad; y el $79 \%$ afirma que resulta ineficaz en alta medida, para prevenir su comisión; y, el $21 \%$ manifiesta lo contrario. El $71 \%$ manifiestan que: la criminalización de las agresiones físicas para prevenir y sancionar resulta ineficaz en alta medida. El $100 \%$ de los magistrados manifiestan que la inaplicación de la suspensión de la ejecución de la pena (artículo 57 del Código Penal, modificado mediante Ley $N^{\circ} 30710$, publicado el 29 de diciembre del 2017), no es una medida idónea y necesaria, para afianzar la prevención de este delito $\mathrm{Y}$ no es adecuada e idónea para neutralizar las causas de éste delito. El 93\% manifiestan que la criminalización es una medida populista. El 57\% manifiestan que la criminalización genera desprotección de la víctima y que la condena a pena privativa de libertad condicional resulta ineficaz. El $79 \%$ que es ineficaz, para la evitación de futuros delitos cometidos por el propio delincuente. El 100\% opina que genera desintegración de la familia y desprotección de la víctima. El 86\% manifiestan que la condena a pena privativa de libertad resulta ineficaz, para la adecuada resocialización del delincuente y el $100 \%$ que agudizará el hacinamiento de la población carcelaria

El 93\% respecto a la imposición de inhabilitación de prohibición de aproximarse o comunicarse con la víctima resulta ineficaz en alta medida, por cuanto, contrastado con la realidad, en lugar de cohesionar a la familia, genera su desintegración y desprotección de la víctima. Asimismo, en esta misma proporción, que la Justicia Restaurativa (Mediación) es una alternativa más idónea y viable a la criminalización de las agresiones contra las mujeres e integrantes del grupo familiar. En la consulta a los abogados, el $87 \%$ manifiestan que la criminalización de las agresiones físicas contra las mujeres e integrantes del grupo familiar, vulnera el Principio de Mínima Intervención del Derecho Penal (Subsidiariedad y Fragmentariedad), el 94\% que vulnera el Principio de Proporcionalidad; el $73 \%$ que vulnera el Principio de Lesividad; el $87 \%$ que resulta ineficaz en alta medida, para prevenir su comisión el 95\% que para prevenir y sancionar su comisión, resulta ineficaz en alta medida, el $84 \%$ que la inaplicación de la suspensión de la ejecución de la pena no es una medida idónea y necesaria, para afianzar la prevención de este delito, el $86 \%$ que es una medida populista y manifestación del Derecho Penal Simbólico, el 73\% que no es adecuada e idónea para neutralizar las causas de éste delito; el 60\% genera desprotección de la víctima; el $73 \%$ que resulta ineficaz en alta medida, para la evitación de futuros delitos cometidos por el propio delincuente; el $86 \%$ que resulta ineficaz en alta medida, por cuanto, contrastado con la realidad, en lugar de evitar su comisión, genera desintegración de la familia y desprotección de la víctima; el 79\% que la condena penal, resulta ineficaz contrastado con la realidad, en lugar de cohesionar a la familia, genera su desintegración y desprotección de la víctima, el $92 \%$ que la condena a pena privativa de libertad efectiva, resulta ineficaz para la adecuada resocialización del delincuente; el 92\% que la inaplicación de la suspensión de la ejecución de la agudizará el hacinamiento de la población carcelaria; el 94\% manifiestan que la Justicia Restaurativa (Mediación) es una alternativa más idónea y 
viable a la criminalización de las agresiones contra las mujeres e integrantes del grupo familiar.

\section{Tabla 1}

\section{Error! Bookmark not defined.Percepción de los magistrados}

\begin{tabular}{|c|c|c|c|}
\hline & & $\mathrm{N}$ & $\%$ \\
\hline $\begin{array}{l}\text { ¿Considera que la criminalización de las agresiones físicas contra las mujeres e } \\
\text { integrantes del grupo familiar, vulnera el Principio de Mínima Intervención del } \\
\text { Derecho Penal (Subsidiariedad y Fragmentariedad)? }\end{array}$ & $\mathrm{Si}$ & 4 & 100,0 \\
\hline \multirow{3}{*}{$\begin{array}{l}\text { ¿Considera que la criminalización de las agresiones físicas vulnera el Principio de } \\
\text { Proporcionalidad? }\end{array}$} & $\mathrm{Si}$ & 12 & 85,7 \\
\hline & No & 2 & 14,3 \\
\hline & Total & 14 & 100,0 \\
\hline \multirow{3}{*}{$\begin{array}{l}\text { ¿Considera que la criminalización de las agresiones vulnera el Principio de } \\
\text { lesividad? }\end{array}$} & $\mathrm{Si}$ & 9 & 64,3 \\
\hline & No & 5 & 35,7 \\
\hline & Total & 14 & 100,0 \\
\hline \multirow{3}{*}{$\begin{array}{l}\text { ¿Considera que el efecto intimidatorio de la criminalización resulta ineficaz en } \\
\text { alta medida, para prevenir su comisión? }\end{array}$} & $\mathrm{Si}$ & 11 & 78,6 \\
\hline & No & 3 & 21,4 \\
\hline & Total & 14 & 100,0 \\
\hline \multirow{3}{*}{$\begin{array}{l}\text { ¿Considera para prevenir y sancionar su comisión, resulta ineficaz en alta medida, } \\
\text { por cuanto, contrastado con la realidad la tasa de incidencia de ésta criminalidad, } \\
\text { se ha incrementado? }\end{array}$} & $\mathrm{Si}$ & 10 & 71,4 \\
\hline & No & 4 & 28,6 \\
\hline & Total & 14 & 100,0 \\
\hline $\begin{array}{l}\text { ¿Considera que la inaplicación de la suspensión de la ejecución de la pena para las } \\
\text { personas condenadas por el delito es una medida idónea y necesaria, para afianzar } \\
\text { la prevención de este delito? }\end{array}$ & No & 14 & 100,0 \\
\hline \multirow{3}{*}{$\begin{array}{l}\text { ¿Considera que la criminalización de las agresiones físicas contra las mujeres e } \\
\text { integrantes del grupo familiar, es una medida populista y manifestación del } \\
\text { Derecho Penal Simbólico,? }\end{array}$} & $\mathrm{Si}$ & 13 & 92,9 \\
\hline & No & 1 & 7,1 \\
\hline & Total & 14 & 100,0 \\
\hline $\begin{array}{l}\text { ¿Considera que la criminalización de las agresiones físicas contra las mujeres e } \\
\text { integrantes del grupo familiar, en el artículo 122-B del Código Penal, es adecuada } \\
\text { e idónea para neutralizar las causas de éste delito? }\end{array}$ & No & 14 & 100,0 \\
\hline \multirow{3}{*}{$\begin{array}{l}\text { ¿Considera que la criminalización de las agresiones físicas contra las mujeres e } \\
\text { integrantes del grupo familiar, en el artículo } 122-B \text { del Código Penal, genera } \\
\text { desprotección de la víctima? }\end{array}$} & $\mathrm{Si}$ & 8 & 57,1 \\
\hline & No & 6 & 42,9 \\
\hline & Total & 14 & 100,0 \\
\hline \multirow{3}{*}{$\begin{array}{l}\text { ¿Considera que la condena a pena privativa de libertad condicional (con reglas de } \\
\text { conducta), resulta ineficaz en alta medida, para la evitación de futuros delitos } \\
\text { cometidos por el propio delincuente? }\end{array}$} & $\mathrm{Si}$ & 8 & 57,1 \\
\hline & No & 6 & 42,9 \\
\hline & Total & 14 & 100,0 \\
\hline \multirow{3}{*}{$\begin{array}{l}\text { ¿Considera que la condena a pena privativa de libertad efectiva, por el delito de } \\
\text { agresiones físicas contra mujeres o integrantes del resulta ineficaz en alta medida, } \\
\text { para la evitación de futuros delitos cometidos por el propio delincuente? }\end{array}$} & $\mathrm{Si}$ & 11 & 78,6 \\
\hline & No & 3 & 21,4 \\
\hline & Total & 111 & 100,0 \\
\hline $\begin{array}{l}\text { ¿Considera usted que la condena penal, por el delito de agresiones físicas contra } \\
\text { mujeres o integrantes del grupo familiar, previsto en el artículo } 122-B \text { del Código } \\
\text { Penal, resulta ineficaz en alta medida, por cuanto, contrastado con la realidad, en } \\
\text { lugar de evitar su comisión, genera desintegración de la familia y desprotección de } \\
\text { la víctima? }\end{array}$ & $\mathrm{Si}$ & 14 & 100,0 \\
\hline \multirow{3}{*}{$\begin{array}{l}\text { ¿Considera que la condena penal, con imposición de inhabilitación de prohibición } \\
\text { de aproximarse o comunicarse con la resulta ineficaz en alta medida, por cuanto, } \\
\text { contrastado con la realidad, en lugar de cohesionar a la familia, genera su } \\
\text { desintegración y desprotección de la víctima? }\end{array}$} & $\mathrm{Si}$ & 13 & 92,9 \\
\hline & No & 1 & 7,1 \\
\hline & Total & 14 & 100,0 \\
\hline \multirow{3}{*}{$\begin{array}{l}\text { ¿Considera que la pena privativa de libertad efectiva, resulta ineficaz en alta } \\
\text { medida, para la adecuada resocialización del delincuente? }\end{array}$} & $\mathrm{Si}$ & 12 & 85,7 \\
\hline & No & 2 & 14,3 \\
\hline & Total & 14 & 100,0 \\
\hline $\begin{array}{l}\text { ¿Considera que la inaplicación de la suspensión de la ejecución de la pena (artículo } \\
57 \text { del Código Penal, modificado mediante Ley } N^{\circ} 30710 \text {, agudizará el } \\
\text { hacinamiento de la población carcelaria }\end{array}$ & $\mathrm{Si}$ & 14 & 100,0 \\
\hline \multirow{3}{*}{$\begin{array}{l}\text { ¿Considera usted que la Justicia Restaurativa (Mediación) es una alternativa más } \\
\text { idónea y viable a la criminalización de las agresiones contra las mujeres e } \\
\text { integrantes del grupo familiar, para la resolución ésta problemática social? }\end{array}$} & $\mathrm{Si}$ & 13 & 92,9 \\
\hline & No & 1 & 7,1 \\
\hline & Total & 14 & 100,0 \\
\hline
\end{tabular}


De los procesos judiciales concluidos, el $60 \%$ de los imputados en los procesos judiciales concluidos por la presunta comisión del delito de agresiones contra mujeres o integrantes del grupo familiar, se le atribuyó la modalidad de agresiones físicas, y al $40 \%$ agresiones físicas y psicológicas. En el $100 \%$ la agresión física contra la agraviada se dio en el contexto de violencia familiar, en el $100 \%$ el agraviado fue agredido en su condición de integrante de grupo familiar, en el $65 \%$ los imputados tienen grado de instrucción de secundaria completa, el $15 \%$ secundaria incompleta y el $20 \%$ superior completa, en el $50 \%$ las agraviadas tienen grado de instrucción de secundaria completa, el 30\% secundaria incompleta, el $10 \%$ primaria incompleta, el $5 \%$ primaria completa y un $5 \%$ superior completa; en el $50 \%$ el agresor y la agraviada tienen una relación de convivientes, el $30 \%$ de ex convivientes, el $5 \%$ de cónyuges, el $5 \%$ de ex cónyuges, el $5 \%$ de ascendientes y $5 \%$ otros; en el $90 \%$ las partes procesales (agresor y agraviada) han procreado hijos, y un $10 \%$ lo contrario, lo que pone en evidencia la desintegración familiar, en el $45 \%$ el agresor y la parte agraviada procrearon 2 hijos, en el $35 \%$ las partes procrearon 1 hijo, en el 5\% procrearon 3 hijos, en el 5\% procrearon 4 hijos y en el 10\% de procesos, las partes no procrearon hijos, en el $20 \%$ el médico legista otorgó a la víctima de agresión física 3 días de incapacidad médico legal, en otro $20 \%$ otorgó 4 días, en un 15\% otorgó 1 día, en un 10\% otorgó 2 días, en un 10\% otorgó 10 días, en el $90 \%$ los imputados no registraban antecedentes penales, en el $70 \%$ concluyeron por Terminación Anticipada, el $25 \%$ concluyó con Proceso Inmediato, aprobando Principio de Oportunidad, en el 35\% concluyeron con sentencia de terminación anticipada (JIP), en el $40 \%$, concluidos por sobreseimiento, se invocó la causal de extinción de la acción penal.

Del total de procesos judiciales concluidos con reserva de fallo condenatorio (8 procesos), en el $77.8 \%$ de los mismos se impuso dicha reserva por el termino de 1 año, en el $11.1 \%$ por el término de 10 meses y en otro $11.1 \%$ por el termino de 11 meses. En el $40 \%$ se sancionó a los agresores con pena privativa de libertad, el $5 \%$ fueron sancionados con 11 meses, el 20\% fueron sancionados con 1 año, el 5\% fueron sancionados con 1 año y 3 meses, el 5\% con 1 año, 3 meses y 3 días, el 5\% fueron sancionado con 1 año y 5 meses; mientras que en el $60 \%$ de procesos judiciales no se ha impuesto pena. En el $75 \%$ sí se impuso reglas de conducta a los sentenciados, en el $65 \%$ no se impuso a los sentenciados la regla de conducta de obligación de someterse a un tratamiento psicológico o psiquiátrico. Se impuso al sentenciado $\mathrm{S} / .500 .00$ Soles de reparación civil en el 35\% de los procesos judiciales concluidos, S/. 1,000.00 Soles en el $20 \%$ de procesos, S/. 300.00 Soles en el $15 \%$ de los procesos, S/. 200.00 Soles en el $15 \%$ de los procesos, S/. 400.00 Soles en el $5 \%$ de procesos, $S / .1,500.00$ en el $5 \%$ de procesos; y sólo en el $5 \%$ de procesos no se impuso reparación civil por haber concluido en sobreseimiento. En el $75 \%$ no se prohibió a los sentenciados aproximarse o comunicarse con la víctima, en el 95\% no se dispuso medidas de protección a favor de la agraviada. 


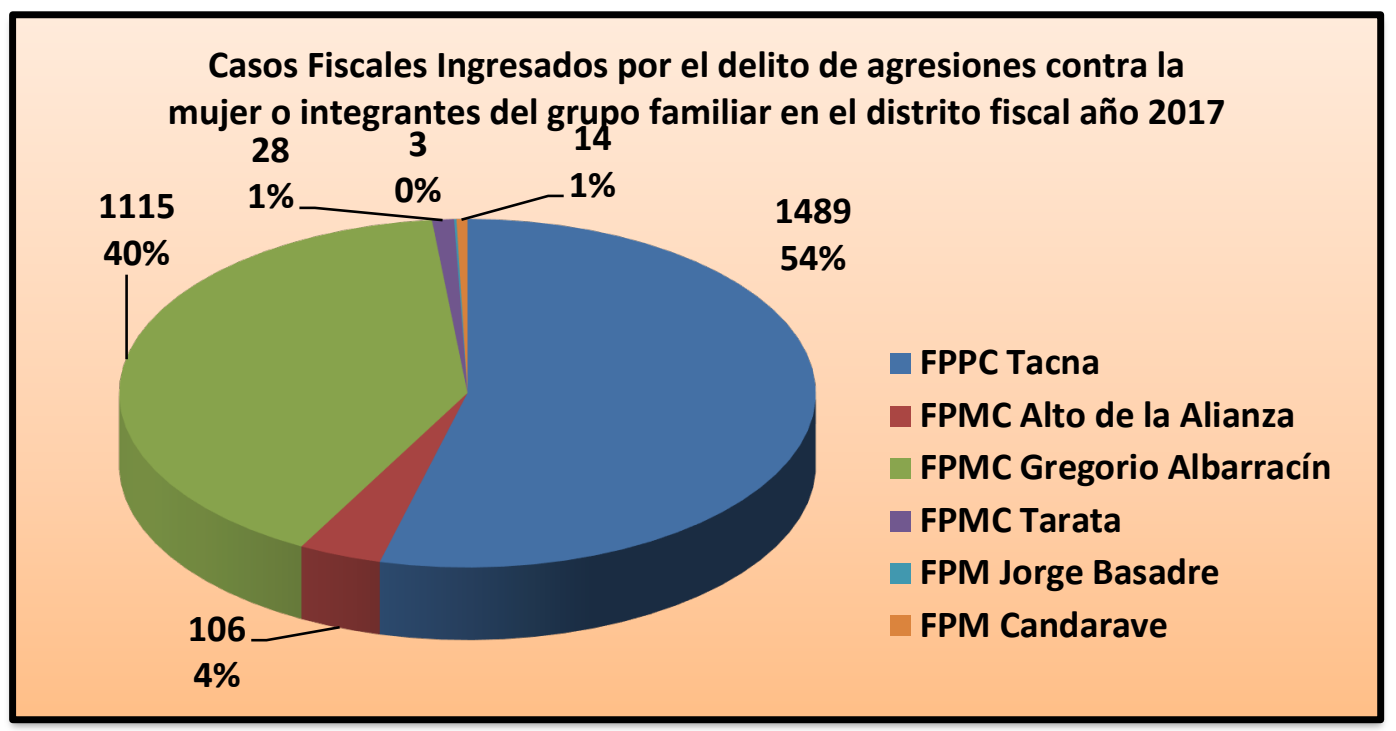

Figura 1

Casos fiscales ingresados por el delito de agresiones contra la mujer o integrantes del grupo familiar en el distrito judicial de Tacna año 2017

En la figura 1 se puede observar la información estadística del delito de agresiones contra la mujer o integrantes del grupo familiar para el período 2017, en la que se puede destacar un elevado número de casos fiscales ingresados en las sedes de Tacna y Gregorio Albarracín; lo que evidencia que el efecto intimidatorio de la criminalización de las agresiones físicas contra mujeres o integrantes del grupo familiar, previsto en el artículo 122-B del Código Penal, resulta ineficaz para disuadir su comisión.

De los casos fiscales ingresados en el distrito judicial de Tacna, que el $79 \%$ se encuentran resueltos y el $21 \%$ se encuentran en trámite.

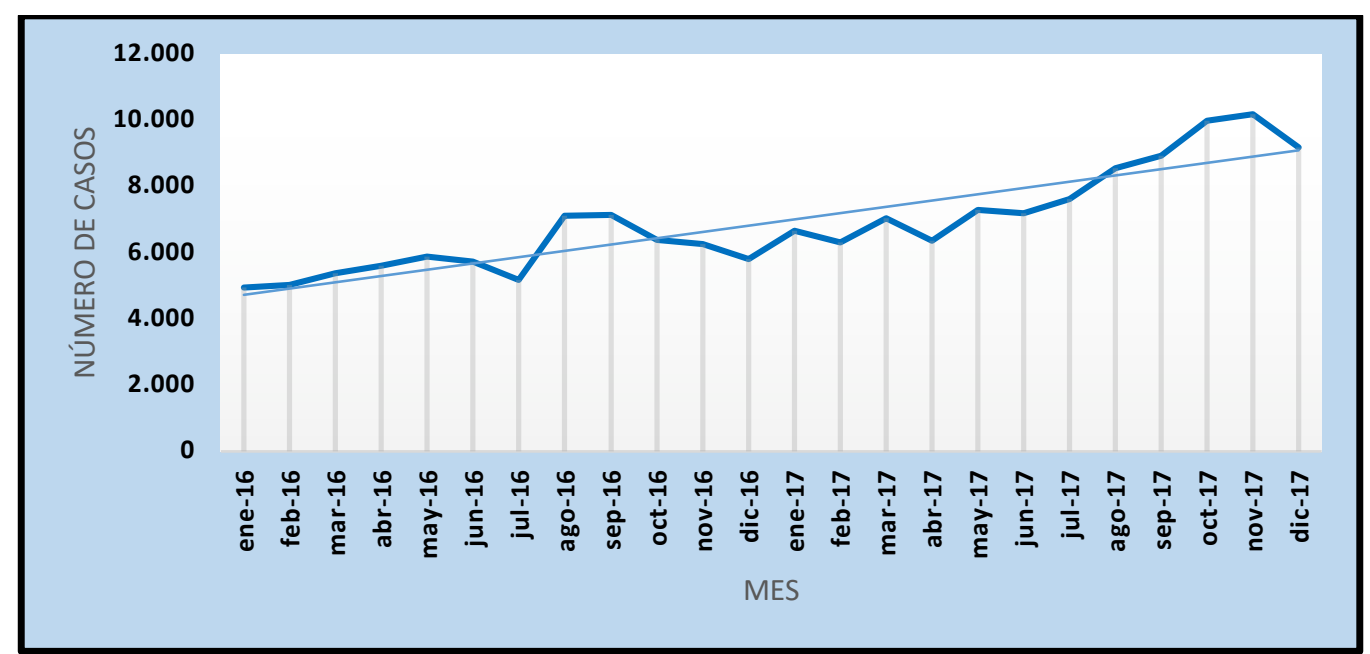

Fuente: Ministerio de la Mujer y poblaciones vulnerables - Sistema de Registro de Casos de los Centros Emergencia Mujer a nivel nacional. Elaboración: Ministerio de la Mujer y poblaciones vulnerables

Figura 2

Variación porcentual de los casos de Violencia Familiar y Sexual atendidos del año 2017 en relación al año 2017 
En la figura 02 se puede observar una tendencia creciente en el año 2017, de 70,510 casos atendidos en el año 2016 a 95,317 casos en el año 2017, hay un incremento de $35.2 \%$, lo que evidencia que el efecto intimidatorio de la criminalización de las agresiones físicas contra mujeres o integrantes del grupo familiar, resulta ineficaz para disuadir su comisión.

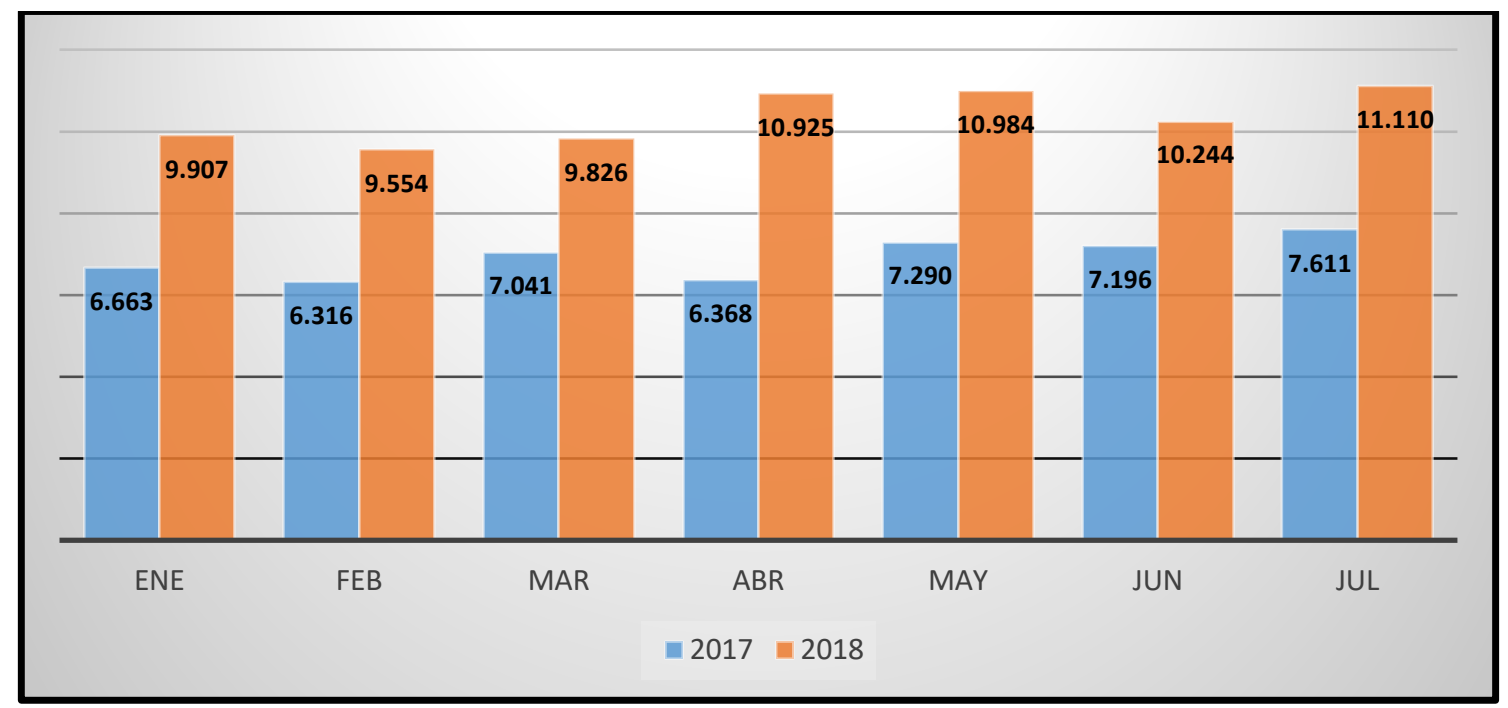

Fuente: Ministerio de la Mujer y poblaciones vulnerables - Sistema de Registro de Casos de los Centros Emergencia Mujer a nivel nacional. Elaboración: Ministerio de la Mujer y poblaciones vulnerables

\section{Figura 3}

Variación porcentual de los casos de Violencia Familiar y sexual atendidos del año 2018 en relación al año 2017

En la figura 03 se puede observar una tendencia creciente en el año 2018, de 48,485 casos atendidos en el primer semestre del año 2017 a 72,550 casos en el primer semestre del año 2018, hay un incremento de $49.6 \%$, lo que evidencia que el efecto intimidatorio de la criminalización de las agresiones físicas contra mujeres o integrantes del grupo familiar, resulta ineficaz para disuadir su comisión.

\section{DISCUSIÓN}

Se comprueba que la criminalización de las agresiones físicas contra mujeres o integrantes del grupo familiar, en el artículo 122-B del Código Penal, resulta ineficaz en alta medida, porque contrastado con la realidad, en lugar de evitar su comisión y afianzar el principio de unidad familiar, genera desintegración de la familia y desprotección de la víctima. El efecto intimidatorio de la criminalización resulta ineficaz para disuadir su comisión y afianzar el mantenimiento del orden familiar y social. La condena a pena privativa de libertad, resulta ineficaz para cumplir con el efecto resocializador de la pena. La criminalización de las agresiones físicas contra mujeres o 
integrantes del grupo familiar, resulta ineficaz, porque contrastado con la realidad, en lugar de evitar su comisión y afianzar el principio de unidad familiar, genera desintegración de la familia y desprotección de la víctima.

Los datos evidencian, el fracaso de la política criminal criminalizadora que, el Estado Peruano, ha diseñado a través de la criminalización de toda conducta que de cualquier modo cause lesiones a una mujer por su condición de tal o a integrantes del grupo familiar que requieran menos de diez días de asistencia o descanso en cualquiera de los contextos previstos en el primer párrafo del artículo 108-B del Código Penal, que, eran controlados civilmente, ahora, sancionados con pena privativa de libertad de uno a tres años, mediante la promulgación del Decreto Legislativo N¹323 (2017), transgrediendo los principios de finalidad preventiva de la pena (Código Penal, 2018, Art. IX) y proporcionalidad de la penas (Código Penal, 2018, Art. VIII), neocriminalizó la violencia familiar, promulgando la Ley $\mathrm{N}^{\circ}$ 30710, publicado el 29 de diciembre del 2017 que modificó el artículo 57 del Código Penal, prescribiendo que la suspensión de la ejecución de la pena es inaplicable para las personas condenadas por el delito previsto en el artículo 122-B del Código Penal (es decir, el agresor cónyuge, conviviente, padre, hermano, etc., ingresará inevitablemente ingresará al establecimiento penitenciario), para prevenir la violencia intrafamiliar, sin embargo, con la muestra de ésta investigación, se ha evidenciado que, tal política criminal, ha resultado populista por criminalizar la violencia familiar, sólo para congraciarse con la sociedad que reclama, toda vez que, la tasa de violencia familiar, no disminuyó, contrariamente, continuó incrementándose de manera alarmante, pues, en el distrito judicial de Tacna, en el año 2017, donde ingresaron 2172 casos, pues en el año 2016 se ingresaron 1374 casos por violencia familiar, y en el 2018 la cifra sigue aumentando, con el ingreso de 5572 casos, lo cual guarda concordancia con el incremento de expedientes Judiciales ingresados por lesiones leves por violencia familiar en el Distrito Judicial de Tacna, del 2010 - SEP. 2018, toda vez que en el Poder judicial en el año 2016, se judicializaron 4 casos, en el 2017 fueron 237 casos y hasta septiembre de 2018, 887 casos. Esta situación viene suscitando a nivel nacional, pues según el Ministerio de la Mujer y poblaciones vulnerables, existe una Variación porcentual de los casos de Violencia Familiar y Sexual atendidos del año 2017 en relación al año 2016, consistente en una tendencia creciente, habiéndose atendido 70,510 casos en el año 2016 y 95,317 casos en el año 2017, existiendo un incremento del $35.2 \%$, asimismo, en cuanto a la Variación porcentual de los casos de Violencia Familiar y sexual atendidos del año 2018 en relación al año 2017 (en el primer semestre de ambos), se observó también una tendencia creciente para el año 2018, de 48,485 casos atendidos, en comparación al año 2017 donde se atendió 72,550 casos en el primer semestre, existiendo un incremento de $49.6 \%$.

Ahora bien, desde la perspectiva de la política penitenciaria de lege ferenda se propone la derogatoria del artículo 122-B del Código Penal, por los efectos criminógenos que viene generando su aplicación, consecuentemente, se modificará el artículo 57 de acotado, quedando derogado en cuanto a la inaplicación de la suspensión de la pena, evitando así, que en lo futuro sea sancionado el Estado por la Corte Interamericana de Derechos Humanos y, como alternativa jurídica, para la solución del problema jurídico investigado, se propondrá la institución de la mediación como mecanismo alternativo 
de solución de la Justicia Restaurativa y reglas para su aplicación, sanciones jurídica sociales justas e implementación de tales políticas, para aminorar las causas del problema investigado, en el marco de una política criminal preventivo y respetuoso de los derechos fundamentales de protección de la familia, establecido en el artículo $4^{\circ}$ de la Constitución Política del Perú.

El Estado debe reorientar su política penal neopunitiva de emergencia a una política penal preventiva y respetuoso de los derechos fundamentales, protección de la familia, afianzando la prevención de la violencia familiar, consecuentemente, el Congreso de la República, debe derogar el artículo 122-B del Código Penal, por su ineficacia. El Poder Legislativo debe dictar la ley de mediación penal, como mecanismo alternativo a la pena, para la solución de conflictos de violencia intrafamiliar, afianzar la efectiva reparación civil de la víctima, tratamiento, psicológica y/o psiquiátrica, para su efectiva reinserción a la comunidad integración y evitar la recaída en la agresión, lo que afianzará la unidad y protección de la familia, por tanto, la propuesta, se erige como resolución jurídico eficiente y eficaz del problema social y comunitario. El Poder Ejecutivo, debe implementar programas en todos los niveles de educación (primaria, secundaria, técnico y superior) que permitan inculcar al ciudadano en valores desde su niñez, orientados a la no violencia contra la mujer e integrantes del grupo familiar, combatiendo sus causas, para neutralizar a mínimos tolerables y afrontar las consecuencias de éste problema social comunitario, con mecanismos alternativos a la pena, por cuanto, ésta no resulta necesaria, ni idónea, como he demostrado en la presente investigación.

\section{REFERENCIAS}

Álvarez, O. (2017). Principales factores jurídico-normativos que permiten la reincidencia de los actos de violencia familiar en el Perú. (Tesis de Doctor en Ciencias, Escuela de Post Grado de la Universidad Nacional de Cajamarca).

Asamblea General de las Naciones Unidas (23 de marzo de 1976). El Pacto Internacional de Derechos Civiles. Recuperado en https://www.minjus.gob.pe/wpcontent/uploads/2014/03/PACTO-INTERNACIONAL-DE-DERECHOS-CIVILES-YPOLITICOS.pdf

Asamblea General de las Naciones Unidas (03 de enero de 1976). El Pacto Internacional de Derechos Económicos, Sociales y Culturales. Naciones Unidas. Recuperado en

Asamblea General de las Naciones Unida (10 de diciembre de 1948). La Declaración Universal de los Derechos Humanos. Naciones Unidas.

Buompadre, Jorge Eduardo (2013). Violencia de género, feminicidio y derecho penal: los nuevos delitos de género. Córdoba, República de Argentina: Alveroni Ediciones

Cabrera D. (2018). El incremento punitivo de la violencia contra la mujer mediante la ley 30364 como expresión del derecho penal de mujeres, en el año 2018. (Tesis de Maestría en Derecho Mención Ciencias Penales, Universidad Nacional Santiago Antúnez De Mayolo).

Castillo J. (2016). Comentarios a la nueva Ley de Violencia Contra las mujeres y los integrantes del grupo familiar. Lima, Perú: Editorial Ubilex Asesores S.A.C.

Castillo, J. (2018). La prueba en el delito de violencia contra la mujer y el grupo familiar. Lima, Perú: Editores del Centro E.I.R.L.

Choclan, J. A. (2005). Teoría de la Pena. En A. y. Calderon C., Derecho Penal. Madrid, España: Bosch. 
Congreso de la República del Perú (23 de noviembre de 2015). Ley que modifica la Ley de Protección frente a la Violencia Familiar. [Ley № 26763]. Diario Oficial El Peruano. Recuperado de

Congreso de la República del Perú (23 de noviembre de 2015). Ley para prevenir, sancionar y erradicar la violencia contra las mujeres y los integrantes del grupo familiar. [Ley № 30364]. Diario Oficial El Peruano.

Congreso de la República del Perú (25 de marzo de 1997). Ley que modifica la Ley de Protección frente a la Violencia Familiar. [Ley № 26763]. Diario Oficial El Peruano.

Congreso de la República del Perú (29 de diciembre de 2017). Ley que modifica el último párrafo del artículo 57 del código penal, ampliando la prohibición del beneficio de la suspensión de la pena efectiva a los condenados por lesiones leves causadas por violencia contra la mujer. [Ley $N^{\circ} 30710$ ]. Diario Oficial El Peruano.

Congreso de la República del Perú (27 de julio de 2016). Decreto Supremo que aprueba el Reglamento de la Ley № 30364, Ley para prevenir, sancionar y erradicar la violencia contra las mujeres y los integrantes del grupo familiar Decreto Supremo № 009-2016MIMP. Diario Oficial El Peruano.

Corral, Y., Corral, I. Y Corral A. (2015). Procedimientos de muestreo. Revista ciencias de la educación, 26 (46), pp. 151-167. Recuperado de https:// dialnet.unirioja,

Del Águila, J. (2017). Violencia Familiar, anásilis y comentarios a la Ley $\mathrm{N}^{\circ} 30364$ y su reglamento D. S. N 009-2016-MIMP. Lima, Perú: Editorial Ubilex Asesores S.A.C.

Díaz, R. \& Mendiazábal, . (2018). Victimología enfoque desde el Derecho Penal y Procesal Penal. Lima, Perú: Grijley E.I.R.L.

Facultad de Ciencias Empresariales, FACEM (2014). Protocolo de Investigación de la Facultad de Ciencias Empresariales. Tacna, Perú: Universidad Privada de Tacna.

Fernández M. (S.f.). La familia vista a la luz de la constitución y los derechos fundamentales: aproximación a un análisis crítico de las instituciones familiares.

García, A. (Coord.). (2011). La violencia contra las mujeres en la pareja: claves de análisis y de intervención. Madrid: Universidad Pontificia Comillas, 2011.

Gálvez, T., \& Rojas, R. (2017). Derecho Penal Parte Especial. Lima, Perú: Jurista Editores E.I.R.L.

González, I. (2013). Justicia restaurativa en violencia intrafamiliar y de género. Revista de derecho (Valdivia) de la Universidad Austral de Chile, XXVI(2), pp. 238-241.

Huaroma, A. (2018). Estudio del Feminicidio en el Perú. Lima, Perú: A\&C Ediciones Jurídicas S.A.C. Hurtado J. y Prado V. (2011), Manual de derecho penal. Parte general. Lima, Perú: Idemsa.

Instituto Nacional de Estadística e Informática - INEI (2018). Encuesta Demográfica y de Salud Familiar - ENDES 2017. Lima, Perú: INEI. Recuperado de

Instituto Nacional de Estadística e Informática y Ministerio de la Mujer y Poblaciones Vulnerables (2016). Infografía de resultados de la ENARES 2015. Lima, Perú: INEI. Recuperado de

Instituto Nacional Penitenciario (Enero de 2018). Informe Estadístico Penitenciario Enero 2018.

IX Conferencia internacional americana (1948). La Declaración Americana de los Derechos y Deberes del Hombre.

Nuñez, W. \& Castillo, M. (2014). Violencia Familiar comentarios a la Ley N²9282. Lima, Perú: Ediciones Legales E.I.R.L

Oficina del alto comisionado de las Naciones Unidas para los Derechos Humanos (19 de abril de 2005). La eliminación de la violencia contra la mujer (2005). Resolución de la Comisión de Derechos Humanos 1

Oficina de las Naciones Unidas contra la droga y el delito (2006). Manual sobre programas de justicia restaurativa. Recuperado de 
Olvera J. (2015). Metodología de la investigación jurídica para la investigación y la elaboración de tesis de licenciatura y posgrado. Toluca, Estado de México: Universidad Autónoma del Estado de México M. A. Porrúa.

Plácido A. (2013). El modelo constitucional de familia, la orientación sexual de los padres y los derechos del hijo. Revista Vox juris, 1 (25), 45-80.

Poder Ejecutivo del Perú (06 de enero de 2017). Decreto legislativo que fortalece la lucha contra el Feminicidio, la violencia familiar y la violencia de género. [Decreto Legislativo $\mathrm{N}^{\circ}$ 1323]. Diario Oficial El Peruano.

Poder Ejecutivo del Perú ( 26 de junio d 1997). Decreto Supremo que aprueba el Texto Único Ordenado de la Ley $\mathrm{N}^{\circ} 26260$, Ley de Protección frente a la Violencia Familiar. [Decreto Supremo $N^{\circ}$ 006-97-JUS]. Diario Oficial El Peruano.

Polaino, A. (2013). Violencia juvenil y violencia familiar. Madrid, España: Ediciones Díaz de Santos.

Polaino, M. (2004). “Derecho Penal” Modernas bases dogmáticas. Lima, Perú: Grijley E.I.R.L.

Programa de maestría en gerencia social - PUCP (2013). Material para el curso de investigación en gerencia social. Lima, Perú: PUPC

Rafael, T. (2017). Ineficacia de las medidas de protección en la nueva ley de violencia familiar Ley $\mathrm{n}^{\circ}$ 30364. (Tesis de Pre Grado, Universidad Privada Antonio Guillermo Urrelo).

Ramón, J. \& De Borafull I. \& Gas, M. \& Echeburua, E. \& De Corral, P. \& De Paúl, J. \& Arruabarrena, M. \& Romero, F. \& Zarate, Cuadros, D. (2010). Violencia Intrafamiliar. Raíces, factores y formas de la violencia en el hogar. Buenos Aires, Argentina: Euros Editores S.R.L.

Rodríguez, F. (2014). La investigación jurídica básica y la investigación jurídica aplicada. Justicia, $2+(25), p p, 8-11$. Recuperado de h'ttp:// www. scielo.org.co

Reátegui, J. \& Reátegui, R. (2017). El delito de Feminicidio en la doctrina y la jurisprudencia. Lima, Perú: Grijley E.I.R.L.

Reyna, L. (2011). Delitos contra la Familia y la violencia doméstica. Lima, Perú: Jurista Editores E.I.R.L.

Rivas, S. (2018). El tipo penal de agresiones entre los integrantes del grupo familiar ¿Es legítimo criminalizar dicha conducta?. Revista Juridica Actualidad Penal (47), pp. 157-158.

Villavicencio, F. (2017). Derecho Penal Parte General. Lima, Perú: Grijley.

Zaffaroni, E. \& Alagia, A., \& Slokar, A. (2005). Manual de Derecho Penal. Buenos Aires, Argentina: Ediar Sociedad Anónima Editora. 